\title{
Immunomodulatory Effects of Different Cellular Therapies of Bone Marrow Origin on Chimerism Induction and Maintenance Across MHC Barriers in a Face Allotransplantation Model
}

\author{
Mikael Hivelin $^{1}$ - Aleksandra Klimczak ${ }^{1,2} \cdot$ Joanna Cwykiel $^{1,3} \cdot$ Erhan Sonmez $^{1}$.

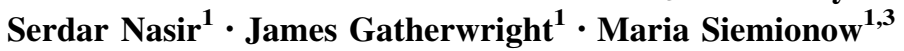

Received: 5 May 2015/ Accepted: 5 October 2015/Published online: 26 December 2015

(C) L. Hirszfeld Institute of Immunology and Experimental Therapy, Wroclaw, Poland 2015

\begin{abstract}
Many more patients would benefit from vascularized composite allotransplantation if less toxic and safer immunosuppressive protocols will become available. Tolerance induction protocols with donor cells co-transplantation are one of the promising pathways to reduce maintenance immunosupressive regimens. We investigated the role of donor bone marrow cells (BMC), mesenchymal stromal cells (MSC) and in vivo created chimeric cells (CC) used as supportive therapies in a fully MHC-mismatched rat face transplantation model. Twenty-four fully MHC-mismatched hemiface transplantations were performed between ACI $\left(\mathrm{RT}^{1}{ }^{\mathrm{a}}\right)$ donors and Lewis (RT1 ${ }^{1}$ ) recipients under combined seven-day immunosuppressive regimen of anti- $\alpha \beta$-T-cell receptor (TCR) monoclonal antibody and cyclosporin A. We studied four experimental groups-group 1: no cellular therapy; group 2: supportive therapy with BMC; group 3: supportive therapy with MSC; group 4: supportive therapy with $\mathrm{CC}$ generated in a primary chimera. We evaluated clinical and histological rejection grades, transplanted cells migration, donorspecific chimerism in the peripheral blood and bone marrow compartments, and $\mathrm{CD} 4^{+} / \mathrm{CD} 25^{+} \mathrm{T}$-cell levels. Face allograft rejection was observed at $26.8 \pm 0.6$ days posttransplant (PT) in the absence of cellular therapy, at $34.5 \pm 1.1$ days for group 2, $29.3 \pm 0.8$ days for group 3,
\end{abstract}

Maria Siemionow

siemiom@uic.edu

1 Department of Plastic Surgery, Cleveland Clinic, Cleveland, $\mathrm{OH}$, USA

2 L. Hirszfeld Institute of Immunology and Experimental Therapy, Polish Academy of Sciences, Wrocław, Poland

3 Department of Orthopedics, University of Illinois at Chicago, Chicago, IL, USA and $30.3 \pm 1.38$ PT for group 4 . The longest survival was observed in allografts supported by co-transplantation of BMC. All support in cellular therapies delayed face allograft rejection by chimerism induction and/or immunomodulatory properties of co-transplanted cells. Survival time was comparable between groups, however, further studies, with different cell dosages, delivery routes and delivery times are required.

Keywords Vascularized composite allograft/ allotransplantation - Face transplantation . Chimerism and tolerance - Bone marrow . Mesenchymal stromal cells $\cdot$ Chimeric cells
Abbreviations
BMC Bone marrow cells
CC Chimeric cells
CsA Cyclosporin A
DRCC Donor-recipient chimeric cells
VCA Vascularized composite allograft
MSC Mesenchymal stromal cells
PE Phycoerythrin
VBM Vascularized bone marrow
PT Post-transplant
TCR T-cell receptor

\section{Introduction}

Vascularized composite allografts (VCA), such as hand or face transplants, are performed across major histocompatibility (MHC) barriers and include different tissue components with specific immunogenic responses. Allogenic skin has been reported to induce an alloimmune 
response in skin grafts (Gibson and Medawar 1943), and skin is considered highly immunogenic in VCA transplantation (Lee et al. 1991; Murray 1971). The suspected high immunogenicity of VCA transplants has led to the clinical use of multi-drug immunosuppressive protocols (Lantieri et al. 2011; Siemionow et al. 2009). Tolerance induction is an approach to reduce the immunosuppressive regimen and its burden. Donor-specific chimerism has been reported in cases of operational tolerance (Starzl et al. 1992). This led to attempts to induce immunomodulation by donor bone marrow cell (BMC) co-transplantation, initially in solid organ (Monaco et al. 1976) and then in VCA (Dubernard et al. 2007; Schneeberger et al. 2013) transplantation. Experimental (Foster et al. 1998; Kawai et al. 1995; Siemionow et al. 2002; Xu et al. 2013) and clinical (Buhler et al. 2002; Kawai et al. 2008) cases of operational tolerance have then been documented. Induction of chimerism and immunomodulation has been assessed using various BMC subsets, including hematopoietic stem cells and mesenchymal stromal cells (MSC) (Mathew et al. 2000). We have developed a VCAface transplantation model (Siemionow et al. 2005) including skin and conjunctiva, cervical lymph nodes, cartilage, without vascularized bone marrow (VBM) component, distinguishing this model from other VCA transplants (Kuo et al. 2009) and allowing to study the effects of co-transplantation of selected cell subsets of donor origin.

In face transplantation model, under a limited 7-day immunosuppresive regimen, we assessed the effects of cellular therapy on chimerism induction and VCA survival by co-transplantation of various BMC populations including: unselected donor $\mathrm{BMC}$, donor MSC, and in vivo created chimeric cells (CCs) harvested from chimeric animals, under our well established 7-day immunodepletive protocol with anti- $\alpha \beta-T$-cell receptor (TCR) monoclonal antibody (mAb) and cyclosporin A (CsA).

\section{Materials and methods}

Inbred 8- to 10-week-old ACI and Lewis rats (Harlan, Indianapolis, Ind.) weighing $200 \mathrm{~g}$ were assigned randomly to experimental groups, in accordance with the Guide for the Care and Use of Laboratory Animals (NIH), with the approval of the Cleveland Clinic Animal Research Committee. Lewis (RT1 ${ }^{1}$ ) rats were used as recipients of fully MHC-mismatched face transplants from ACI (August Copenhagen Irish) $\left(\mathrm{RT}^{\mathrm{a}}{ }^{\mathrm{a}}\right)$ donor rats. Intraperitoneal phenobarbital $(40 \mathrm{mg} / \mathrm{kg})$ and subcutaneous buprenorphine $(0.25 \mathrm{mg} / \mathrm{kg})$ were used for anesthesia and analgesia, respectively.

\section{Experimental Groups and Immunosuppressive Therapy}

Twenty-four face allotransplantations were performed across MHC barrier (ACI $\left(\mathrm{RT}^{\mathrm{a}}{ }^{\mathrm{a}}\right.$ )-Lewis $\left(\mathrm{RT} 1^{1}\right.$ ) in four experimental groups (Table 1) under a 7-day protocol of combined anti- $\alpha \beta$-TCR mAb (clone R73, BD Pharmingen, San Diego, Calif, USA) (250 mg/day/intraperitoneally) and CsA (Bedford Laboratories, Bedford, Ohio, USA) (16 mg/ $\mathrm{kg} /$ day/subcutaneously). Isotransplantations performed between Lewis rats, served as controls.

\section{Isolation of Donor BMCs}

BMC were flushed from ACI $\left(\mathrm{RT}^{\mathrm{a}}\right)$ femoral bones in alpha-MEM medium with $2 \mu \mathrm{g} / \mathrm{ml}$ gentamicin, filtered, mixed with $0.85 \% \mathrm{NH}_{4} \mathrm{Cl}$ for $5 \mathrm{~min}$, centrifuged, washed and resuspended in phosphate-buffered saline (PBS). The cell viability was assessed by trypan blue exclusion. In group 2, $100 \times 10^{6}$ unselected BMC cells (in $50 \mu \mathrm{l}$ PBS) were transplanted into the bone marrow cavity of recipients. In group 3, BMC were cultured to obtain MSC, and in group $4,100 \times 10^{6} \mathrm{BMC}$ was transplanted into the bone marrow cavity of naïve Lewis rats to create primary chimeras.

\section{MSC Expansion in Culture and Phenotype Characterization}

BMC were prepared as above: red blood cells were lysed and $\mathrm{ACI}\left(\mathrm{RT}^{\mathrm{a}}{ }^{\mathrm{a}}\right) \mathrm{BMC}$ were resuspended in alpha-MEM supplemented with $10 \%$ fetal bovine serum (Omega Scientific, Tarzana, CA), $2 \mathrm{mM}$ L- glutamine, $100 \mathrm{U} / \mathrm{ml}$ penicillin, $100 \mathrm{mg} / \mathrm{ml}$ streptomycin and $25 \mathrm{ng} / \mathrm{ml}$ amphotericin $\mathrm{B}$, in $75 \mathrm{~cm}^{2}$ flasks, which were then incubated at $37{ }^{\circ} \mathrm{C}$ under $5 \% \quad \mathrm{CO}_{2}$ atmosphere. Non-adherent cells were discarded by replacing the medium three times per week. For passage, adherent cells at $70 \%$ confluence were detached with $2 \mathrm{ml} 0.25 \%$ trypsin/EDTA, washed in PBS and replated at a density of $1 \times 10^{4}$ cells $/ \mathrm{cm}^{2}$. After the fifth passage, plastic-adherent cells were positive for MHC class I (RT1 $\left.{ }^{\mathrm{a}}\right)$, CD90 and CD29 and negative for CD45RA, CD11b/c and CD31 (Fig. 1). Adipogenic and osteoblastic differentiation potential (Dominici et al. 2006) (Fig. 1) of MSC from passage 5 (P5) were tested in six-well plates $\left(5000\right.$ cells $\left./ \mathrm{cm}^{2}\right)$, in the appropriate induction medium as proposed by the International Society for Cellular Therapy (Dominici et al. 2006). Adipogenic differentiation was confirmed by Oil Red-O (Sigma Aldrich, St. Louis, MO, USA) staining (Fig. 1c), whereas osteogenic differentiation was proved by Alizarin Red staining (Fig. 1b). MSC for intraosseous injection were recovered from P5 to P8 and resuspended in PBS at a density of $8 \times 10^{6}$ cells $/ \mathrm{ml}$. 
Table 1 Experimental groups and immunosuppressive treatment

\begin{tabular}{|c|c|c|c|c|}
\hline $\begin{array}{l}\text { Group (number of } \\
\text { animals) }\end{array}$ & $\begin{array}{l}\text { Cell supportive } \\
\text { therapy }\end{array}$ & Number of cells & Transplant MHC mismatch & Immunosuppressive treatment \\
\hline Control group $(N=6)$ & No cell therapy & & Isotransplantation $^{\mathrm{a}}$ & No immunosuppressive therapy \\
\hline Group $1(n=6)$ & & & Fully MHC class I & Anti- $\alpha \beta$-TCR mAb $(250 \mu \mathrm{g} /$ day $)$ plus \\
\hline Group $2(n=6)$ & $\mathrm{BMC}$ & $100 \times 10^{6}$ & mismatch $^{\mathrm{b}}$ & CsA $(16 \mathrm{mg} / \mathrm{kg} /$ day) 7 days \\
\hline Group $3(n=6)$ & BMSC & $5 \times 10^{6}$ & & \\
\hline Group $4(n=6)$ & $\mathrm{D} / \mathrm{RCC}$ & $10 \times 10^{6}$ & & \\
\hline
\end{tabular}

${ }^{a}$ Hemiface isotransplantation from Lewis $\left(\mathrm{RT} 1^{1}\right)$ to Lewis $\left(\mathrm{RT} 1^{1}\right)$

${ }^{\mathrm{b}}$ Fully MHC class I mismatched hemiface transplantation ACI $\left(\mathrm{RT} 1^{\mathrm{a}}\right)$ to Lewis $\left(\mathrm{RT} 1^{1}\right)$

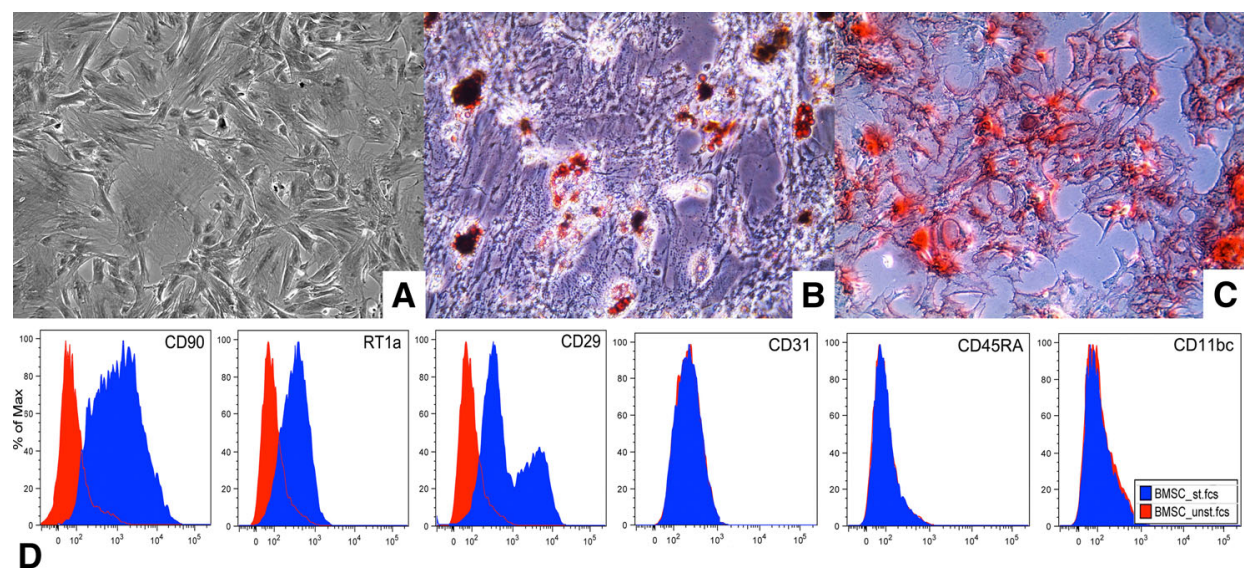

Fig. 1 Preparation of donor mesenchymal stromal cells (MSC) from ACI bone marrow and assessment of the adipogenic, osteogenic, differentiation potentials of cultured MSC. Cultured MSC collected for intraosseous injection, at confluence (5-8 passages), (a). Cells were positively stained with Alizarin Red (ARS) after osteogenic

\section{Positive Selection of CC of Donor Origin from Primary Chimeras and Isolation of Donor/ Recipient CC}

Primary chimeras were created by intraosseous injection of $100 \times 10^{6}$ BMC from ACI donors to Lewis recipients under 7-day of $\alpha \beta$-TCR/CsA immunosuppressive protocol. $\mathrm{BMC}$ were isolated from the femur and tibia of the primary chimeras at 21 days post transplant (PT), as described above, and stained with FITC-conjugated mouse anti-rat antibody specific for donor cells RT $1^{\text {a }}$ MHC class I (ACI) (clone C3, BD Pharmingen, San Diego). Cells were washed and incubated with magnetic beads conjugated with mouse anti-FITC-mAb (Miltenyi Biotec Inc., Auburn, CA, US), washed, and run on LS separation columns (Miltenyi Biotec Inc) for magnetic-activated cell sorting (MACS). The columns were then washed with buffer to collect the donor MHC class I $\left(\mathrm{RT}^{\mathrm{a}}{ }^{\mathrm{a}}\right.$ )-positive cells (positive selection), including lymphocytes, hematopoietic progenitors induction (b) or with Oil Red $\mathrm{O}$ after adipogenic induction (c). FACS analyses confirmed rat MSC to be positive for CD90, MHC class I $\left(\mathrm{RT}^{\mathrm{a}}\right.$ ), and CD29, and negative for CD31, CD45RA, and CD11b/c (d)

and MSC. Flow cytometry analysis confirmed the donor origin of the cells $\left(\mathrm{RT}^{\mathrm{a}+}\right)$. Moreover, $17-50 \%$ of cells carried both donor $\left(\mathrm{RT}^{\mathrm{a}}{ }^{\mathrm{a}}\right)$ and recipient $\left(\mathrm{RT} 1^{\mathrm{l}}\right)$ MHC class I, (Clone B5, BD Pharmingen, San Diego) antigens (Fig. 2). These cells were determined as donor-recipient CC (DRCC). The highest number of the DRCC harvested by MACS was obtained at 21 days after primary chimera creation. They accounted for $11 \times 10^{6}-14 \times 10^{6}$ of cells of donor origin (50-60\% purity). We selected this fraction of cells of donor origin and characterized their immature phenotype $\left(\mathrm{CD} \mathrm{O}^{+}\right)$and donor/recipient MHC class I characteristics $\left(\mathrm{RT} 1^{\mathrm{a}} / \mathrm{RT} 1^{\mathrm{l}}\right)$.

\section{Face Transplantation Procedure}

Composite hemiface allografts were transplanted across MHC barrier, based on the common carotid artery and external jugular vein and, using standard microsurgical techniques (Fig. 3), as previously reported (Siemionow et al. 2005). 


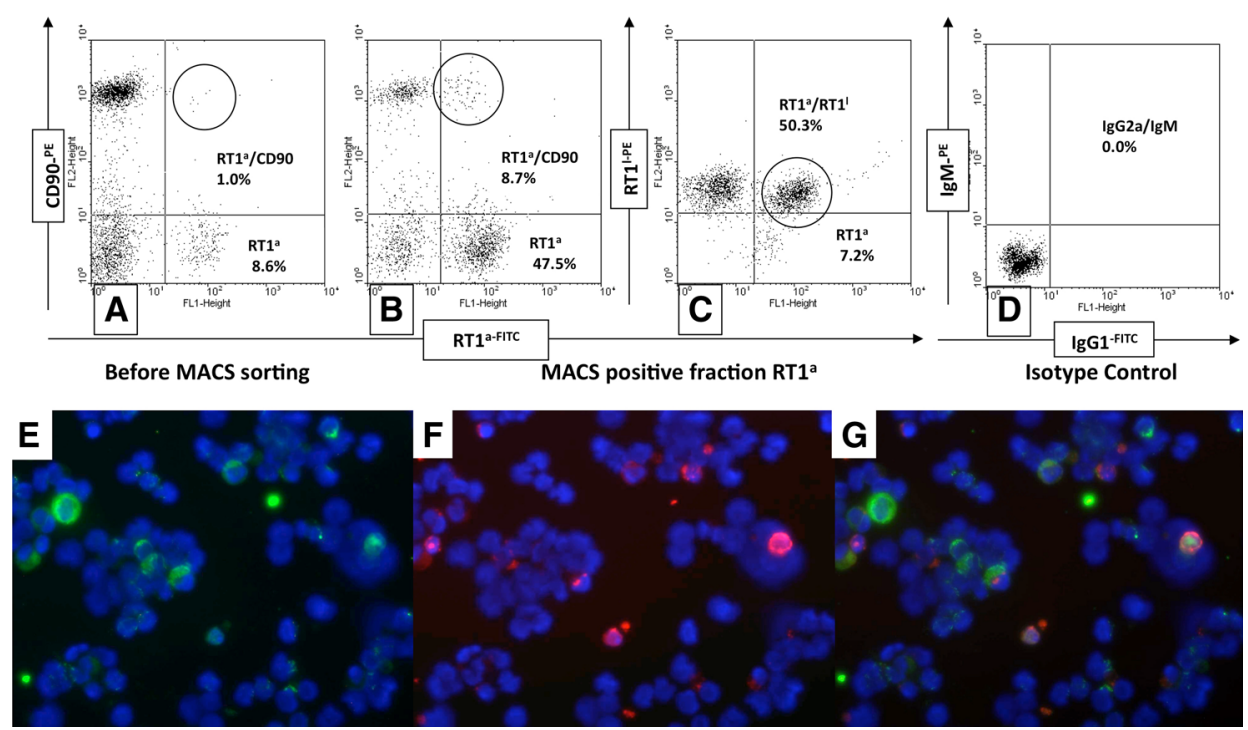

Fig. 2 Positive selection of chimeric cells (CC) (or donor-origin cells) by magnetic sorting (MACS) from a primary chimera and isolation of donor/recipient chimeric cells (DRCC). a Before MACS, $\mathrm{ACI}\left(\mathrm{RT}^{\mathrm{a}+}\right)$ cells in the Lewis recipient rat bone marrow; $\mathbf{b}$ after MACS, ACI $\left(\mathrm{RT}^{\mathrm{a}+}\right)$ in the positive fraction; $\mathbf{c}$ after MACS, ACI
$\left(\mathrm{RT}^{\mathrm{a}+}\right) /$ Lewis $\left(\mathrm{RT}^{1+}\right)$ cells in the positive fraction; d isotype control; e immunofluorescent staining of the MACS-positive fraction: $\mathrm{RT}^{\mathrm{a}+}$ cells; $\mathbf{f}$ immunofluorescent staining of the MACS-positive fraction: RT $1{ }^{1}$ cells; $\mathbf{g}$ combined image illustrating the double MHC class I positive $\left(\mathrm{RT}_{1} \mathrm{a}^{+} / \mathrm{RT} 1 \mathrm{1}^{+}\right)$DRCC
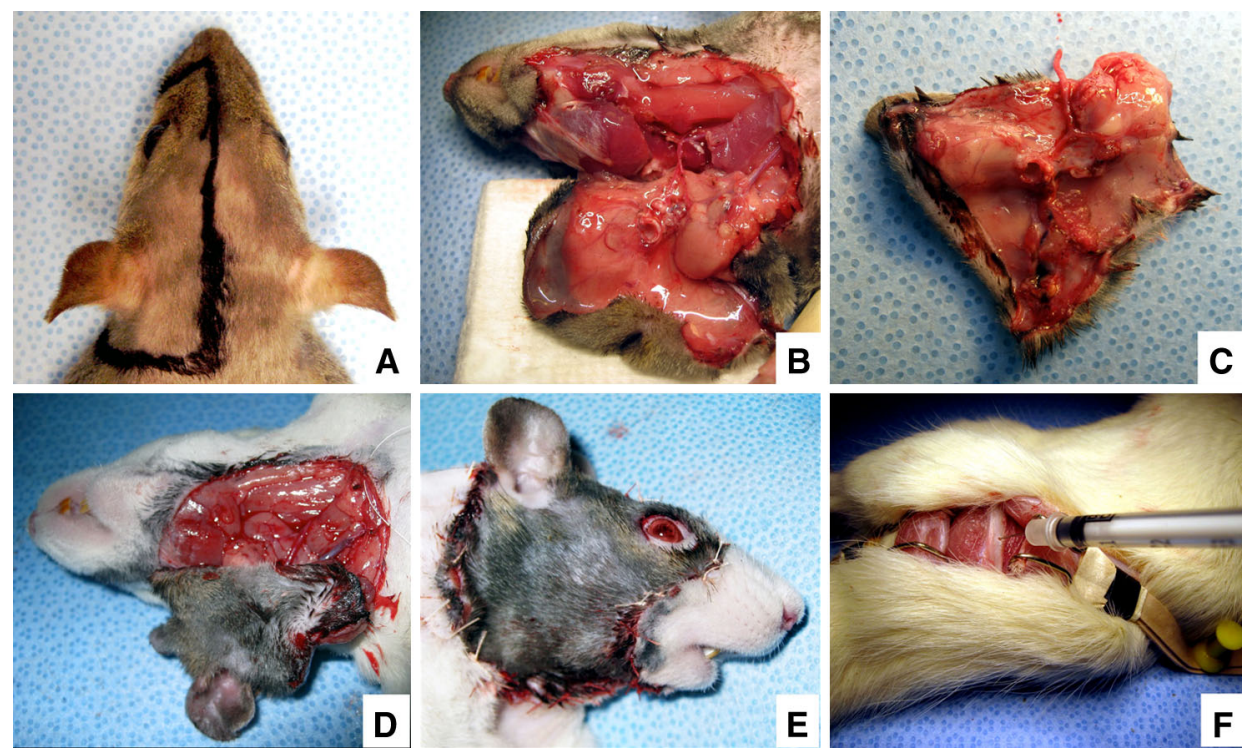

Fig. 3 Transplantation procedure and intraosseous cell injection. a ACI donor rats; $\mathbf{b}$ composite hemifacial transplants vascularized on the external jugular vein and common carotid artery; c transplant including the external ear and scalp, consisting of skin, subcutaneous tissue, cartilage and cervical lymph nodes; $\mathbf{d}$ end-to-side and an end-

\section{Intraosseous Cell Delivery of Cell Therapy}

A hole was drilled into the femoral bone, $50 \mu \mathrm{l}$ of bone marrow was aspirated and cell suspensions were injected intraosseously, as previously described (Klimczak et al. 2007) (Fig. 3f) immediately after completing the face transplant inset. to-end fashion anastomosis on the common carotid artery and external jugular vein, respectively; e transplant sutured; $\mathbf{f}$ after bone marrow aspiration $(0.2 \mathrm{ml})$ from the femoral medulla to facilitate display and prevent supraphysiologic compartment pressures: cells injection (27gauge needle) and hole sealing with wax before skin closure

\section{Clinical and Histological Evaluation of Face Allograft Rejection}

Clinical monitoring was performed daily until the end point (grade 3 rejection). Erythema and hair loss were associated with histological rejection grades 1 and 2, respectively, whereas ulceration, progressive graft shrinkage, and loss of 
pliability indicated complete rejection. Per protocol skin biopsies were performed on days 7, 21, and at euthanasia. Rejection was assessed histologically, by hematoxylineosin staining, and was graded as reported (Buttemeyer et al. 1996; Jones et al. 2001). Normal histological findings were graded 0 (no rejection). Focal epidermal mononuclear cell infiltration and basal cell vacuolation with mild lymphocytic infiltration in the upper dermis was graded 1 (mild rejection), suprabasal bulla formation in the epidermis, with mixed infiltrate in the dermis, was graded 2 (moderate rejection), and epidermal necrosis, with mixed cell infiltrate and vasculitis in the dermis, was graded 3 (severe rejection).

\section{Immunohistochemical Assessment of Donor Cell Migration into the Lymphoid and Non-Lymphoid Organs of the Face Transplant Recipients}

Immunohistochemical staining was performed on the skin, liver, spleen, lymph nodes and thymus of recipients with mouse anti-rat RT1 ${ }^{\mathrm{a}}$ mAb (ACI MHC class I, Pharmingen) as detailed previously (Siemionow et al. 2005). Primary antibody binding was detected with a Dako EnVision kit (Dako North America, Inc., Carpinteria, CA, USA).

\section{Flow Cytometry Analysis of Donor-Specific Chimerism in the Peripheral Blood and Bone Marrow Compartment of Face Transplant Recipients}

Chimerism in the peripheral blood and donor cell migration into the recipient bone marrow (BM) compartment of the face transplant recipients was assessed on days 7 and 21 PT and at euthanasia. Combinations of conjugated mouse antirat $\mathrm{RT} 1{ }^{\mathrm{a}}$-FITC (for donor MHC class I, clone $\mathrm{C} 3$, Pharmingen) with CD4-PE (clone OX-35), CD8-PE (clone OX-8), and CD45RA-PE (clone OX-33), CD90 (clone OX7) were used to assess the donor chimerism levels, and double staining of CD4-PE/CD25-FITC (clone OX-39) for regulatory lymphocytes subset. Anti-rat CD45RA mAb (Clone OX-33) reacts with a high-molecular-weight form of CD45 found only on B lymphocytes, has been used as a marker for rat B lymphocytes (Woollett et al. 1985). Negative control panels were tested, with isotype-matched antibodies ( $\left.\mathrm{IgG}_{1}-\mathrm{FITC} / \mathrm{IgG}_{2}-\mathrm{PE}\right)$ and PBS samples. FACS analysis was performed on $1 \times 10^{4}$ cells with BD FACS SCAN $^{\circledR}$ and CellQuest ${ }^{\circledR}$ software (Beckton-Dickinson, Franklin Lakes, NJ, USA).

\section{Statistics}

The number of animal samples was estimated for a superiority trial (Hackshaw 2009), with two-tailed tests and a
$5 \%$ alpha risk at $80 \%$ power, as follows: $N=F \times 2 / D^{2}$; $D=(\mathrm{M} 2-\mathrm{M} 1) / \mathrm{SD}$, where $N$ : number of subjects in each arm; $F$ : 8 for $80 \%$ power; $D$ : standardized difference; M1: expected value for the standard treatment; M2: expected value of the new treatments; SD: standard deviation. We assumed a standard deviation of $10 \%$ (6 days) of the mean survival of 60 days obtained in our previous study on free vascularized skin transplantation in a fully MHC-mismatched (ACI to Lewis) experimental model under 7-day $\alpha \beta$-TCR and CsA regimen (Demir et al. 2005). An expected $30 \%$ increase in survival on cell therapy would result in a need for 5.3 rats per group (rounded to 6) to observe a significant difference. Transplant survival was compared in log-rank tests, with JMP 5.1.21 software (SAS Institute, Cary, NC), considering a $p$-value $<0.05$ to be significant (Fig. 4).

\section{Results}

\section{Clinical and Histological Outcomes of the Face Allograft Transplant Recipients}

Other than the animals suffering technical failure (thrombosis) during establishment of the experimental model, all the isotransplantation controls survived indefinitely and were euthanized at 10 months PT. Allograft rejection occurred between 25 and 29 days PT (mean \pm SD: $26.8 \pm 0.6$ ) in group 1 (controls-no cell therapy) 31-38 days PT $(34.5 \pm 1.08)$ in group 2 (BMC), 27-32 days PT $(29.3 \pm 0.8)$ in group 3 (MSC), and 25-34 days PT $(30.3 \pm 1.38)$ in group 4 (DRCC). The allografts survived significantly longer in all groups with cell support therapy compared to the controls (no cell therapy) (log-rank test: $p=0.0005$ for BMC, $p=0.0298$ for MSC, $p=0.0256$ for DRCC) (Fig. 4). The allograft survival was significantly longer with $\mathrm{BMC}$ than with MSC (BMC vs. MSC: $p=0.0022$ ) or CC (BMC vs. DRCC: $p=0.0344)$ therapy. BMC therapy increased survival by $30 \%(26-34$ days $=30.8 \%)$. The allograft survival did not differ between the MSC and CC groups (group 3 vs. group 4: $p=0.2276$ )

There was no evidence of graft-versus-host-disease (GvHD) in any group. Histological findings were normal for the epidermis and dermis of all skin biopsy specimens from all groups obtained before day 7 (grade 0). After days 7 PT, the lymphocytic infiltrate in the upper dermis was consistent with grade 1 rejection (Fig. 4a). On days 21 (group 1) and 26 (group 2) PT, epidermal edema with mixed (lymphocytic and neutrophilic) infiltrates in the upper dermis was observed, together with suprabasal bulla formation and moderate perivascular mononuclear cell infiltrate in the dermis, corresponding to grade 2 rejection 


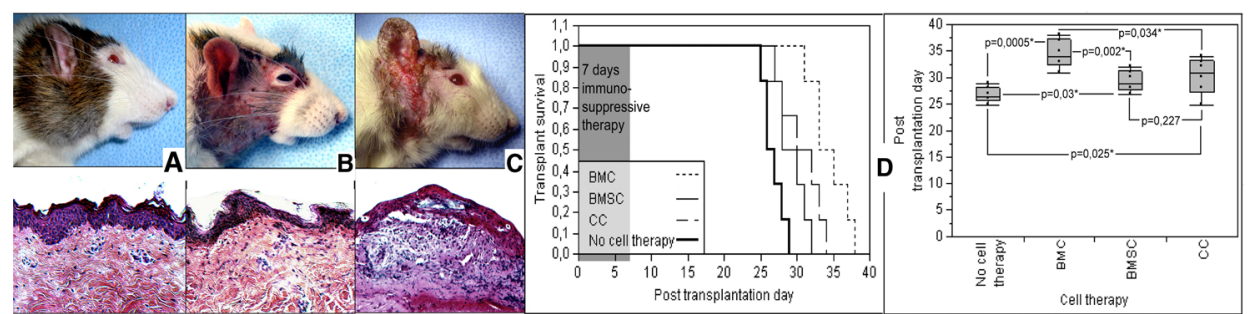

Fig. 4 Rejection of the facial transplant: clinical and histological evaluation and time interval between transplantation and complete rejection. a, b Erythema or hair loss signaled the onset of rejection associated with histological grades 1 and 2, respectively. c Complete rejection: ulceration, progressive shrinkage, and loss of pliability. d Rejection occurred at 25-29 days PT in the controls (group 1; no cell therapy) (mean $\pm \mathrm{SD}: 26.8 \pm 0.6$ ), at 31-38 days PT $(34.5 \pm 1.08)$ in group 2 (BMC), at $27-32$ days PT $(29.3 \pm 0.8)$ in

(Fig. 4b). Biopsy specimens from rejected transplants showed epidermal necrosis typical of grade 3 rejection (Fig. 4c).

\section{Immunohistochemical Evaluation of Donor Cell Migration in the Recipient Lymphoid Organs and Non-Lymphoid Tissues}

At euthanasia, donor-derived ACI $\left(\mathrm{RT}^{\mathrm{a}}{ }^{\mathrm{a}}\right)$ cells displayed similar distribution in the skin, thymus, spleen (white pulp), and B- and T-cell zones of the lymph nodes, but not in the liver of the transplant recipients (Fig. 5) for all cell therapies.

\section{Flow Cytometric Analysis of Donor-Specific Chimerism in the Peripheral Blood and Bone Marrow Compartment of Face Allograft Recipients}

\section{Peripheral Blood Analysis of Donor Chimerism}

At 7 days PT, the total donor chimerism in all groups ranged $42.41-66.53 \%$ of the $\mathrm{RT} 1^{\mathrm{a}+}$ cells of the post-depletional fractions of $\mathrm{T}$ lymphocytes (CD4, CD8), B lymphocytes (CD45RA), and granulocyte monocytes (CD11b/c) (Fig. 5). Co-transplantation of BMC resulted in higher levels of donor chimerism for T cells, B cells, and granulocyte macrophages cells: $63.90 \%$ for $\mathrm{RT} 1^{\mathrm{a}+} / \mathrm{CD} 4^{+}$ cells, $46.73 \%$ for $\mathrm{RT}^{\mathrm{a}+} / \mathrm{CD}^{+}$cells, $1.77 \%$ for $\mathrm{RT}^{\mathrm{a}+} /$ $\mathrm{CD}^{2} 5 \mathrm{RA}^{+}$cells and $60.66 \%$ for $\mathrm{RT}^{\mathrm{a}+} / \mathrm{CD} 11 \mathrm{~b} / \mathrm{c}^{+}$cells. At 21 days PT, the values were as follows: $12.29 \%$ for $\mathrm{RT}^{\mathrm{a}+} / \mathrm{CD}^{+}{ }^{+}, 6.14 \%$ for $\mathrm{RT}^{\mathrm{a}+} / \mathrm{CD}^{+}$cells, $2.42 \%$ for $\mathrm{RT}^{\mathrm{a}+} / \mathrm{CD} 45 \mathrm{RA}^{+}$cells, and $9.61 \%$ for $\mathrm{RT}^{\mathrm{a}+} / \mathrm{CD} 11 \mathrm{~b} / \mathrm{c}^{+}$ cells. At 35 days PT they were $23.66 \%$ for $\mathrm{RT} 1^{\mathrm{a}+} / \mathrm{CD} 4^{+}$ cells, $11.75 \%$ for $\mathrm{RT}^{\mathrm{a}+} / \mathrm{CD}^{+}$cells, $2.82 \%$ for $\mathrm{RT}^{\mathrm{a}+} /$ $\mathrm{CD}^{2} 5 \mathrm{RA}^{+}$cells and $19.74 \%$ for $\mathrm{RT}^{\mathrm{a}+} / \mathrm{CD} 11 \mathrm{~b} / \mathrm{c}^{+}$cells.

After transplantation, the chimerism levels in the peripheral blood of face allograft recipients decreased for group 3, and 25-34 days PT $(30.3 \pm 1.38)$ in group 4 (d). Survival was significantly higher in all cell therapy groups than in the control group (no cell therapy) (log-rank test: $p=0.0005$ for BMC, $p=0.0298$ for MSC, $p=0.0256$ for CC). The BMC groups had the latest onset of transplant necrosis and significantly longer survival than the MSC group (BMC vs. MSC: $p=0.0022$ ) or CC (BMC vs. CC: $p=0.0344)$. Transplant survival was similar after MSC and chimeric cell (CC) injections (MSC vs. CC: $p=0.2276$ )

all cell lineages, reaching their lowest level on day 21 PT. The early development of donor-specific chimerism was observed in both the T-cell and B-cell lineages. By day 21, the T-cell chimerism had declined, replaced by a B-cell based donor chimerism (Fig. 5a).

Group 2 (BMC) displayed significantly higher levels of B-cell peripheral blood chimerism than the other groups. The higher levels of chimerism in the $\mathrm{CD}_{45 \mathrm{RA}}{ }^{+} \mathrm{B}$-cell lineage were observed at 7 days PT and increased until complete allograft rejection, illustrating the engraftment and proliferation of donor B-progenitors or precursors. On day $21 \mathrm{PT}$, the chimerism levels in the BMC group were three times higher compared to MSC group (group 3) and seven times higher compared to the control group. On days 7, 21, and 35 PT, and at euthanasia, the levels of B-cell chimerism $\left(\mathrm{RT}^{\mathrm{a}+} / \mathrm{CD} 45 \mathrm{RA}^{+}\right.$cells) were $0.44,0.36,0.22$ and $0.22 \%$, respectively, for group $1 ; 1.77,2.42,2.82$ and $0.325 \%$ for group 2 (BMC); 1.38, 0.75, 0.96 and $0.22 \%$ for group 3 (MSC) and 1.01, 0.36, 1.24 and $1.26 \%$ for group 4 (CC) (Fig. 5).

\section{Bone Marrow Compartment}

In all groups, the donor cell engraftment into the recipient $\mathrm{BM}$ compartment was confirmed by the presence of $\mathrm{RT} 1^{\mathrm{a}+}$ cells. As expected, the recipients receiving a cell therapy showed 10-15 times higher levels of donor origin cells, compared to the controls (group 1). On day 7, in all study groups, about 1.56-2.74\% of the cells of donor origin in the BM compartment presented an immature $\mathrm{CD}^{+} 0^{+} /$ $\mathrm{RTl}^{\mathrm{a}+}$ phenotype (Fig. 5). On day $21 \mathrm{PT}$, the chimerism in the recipient $\mathrm{BM}$ compartment decreased in all experimental groups, reaching levels ranging 1.09-5.63\% for total BMC chimerism at euthanasia. Over the time, the proportion of cells of donor origin with an immature phenotype also declined, from 0.43 to $0.88 \% \mathrm{RTl}^{\mathrm{a}+} / \mathrm{CD}^{+}$ cells at euthanasia. 


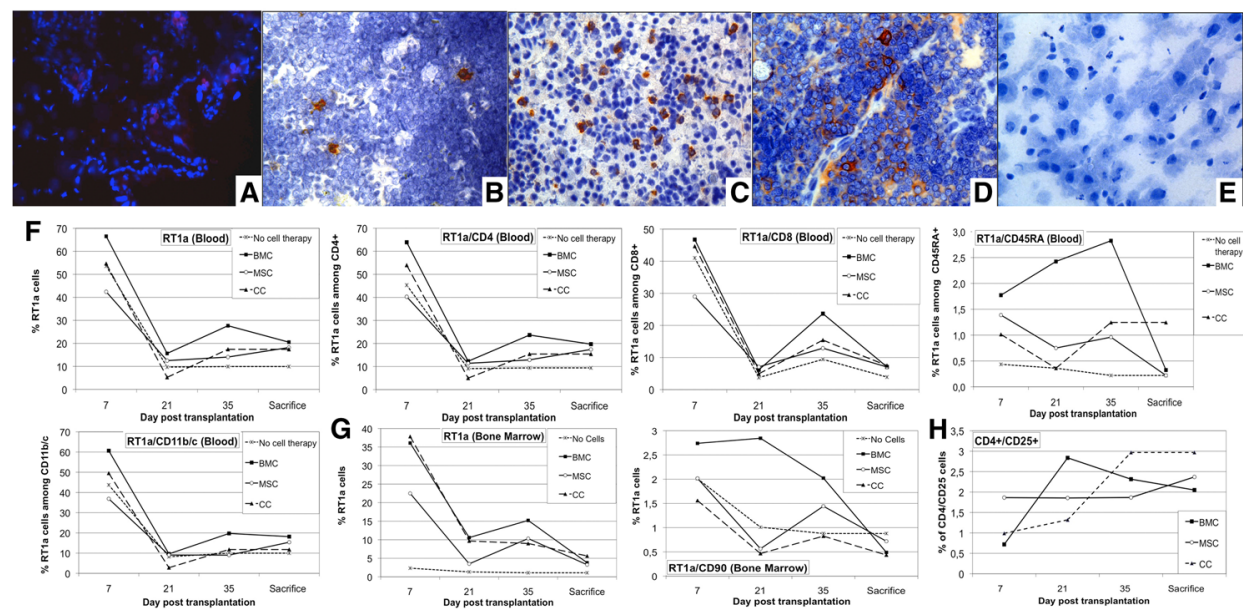

Fig. 5 Donor-origin cells engraftment (immunohistochemistry and flow-cytometry) and evolution of $\mathrm{CD} 4^{+} / \mathrm{CD} 25^{+}$T-cell levels. Immunocytochemical labelling of donor-origin $\left(\mathrm{RT}^{\mathrm{a}+}\right)$ cells engrafted in recipient skin (a), thymus (b), spleen (white pulp) (c) and lymph nodes (d), but not in the liver (e); representative samples from Group 2 on PT day 37 (euthanasia). Kinetics of donor-

\section{Evaluation of $\mathrm{CD}^{+} / \mathrm{CD} 25^{+}$Cell Levels}

The $\mathrm{CD} 4^{+} / \mathrm{CD} 25^{+}$T-cell levels, peaked on day $21 \mathrm{PT}$, at $3.13 \%$ for the BMC group, $2.66 \%$ for the MSC group, and $2.7 \%$ for the $\mathrm{CC}$ group, with no significant differences between groups (Fig. 5). The $\mathrm{CD} 4^{+} / \mathrm{CD} 25^{+}$cell levels then increased slightly during rejection episodes.

\section{Discussion}

The co-transplantation of donor BMC was tested to promote allograft survival, both experimentally (Foster et al. 1998; Kawai et al. 1995; Siemionow et al. 2002; Xu et al. 2013) and clinically (Buhler et al. 2002; Kawai et al. 2008; Schneeberger et al. 2013). We transplanted BMC, MSC, and in vivo created $\mathrm{CC}$ of donor origin as a supportive therapy in a VCA model. The donor cells migrated to the blood, BM, skin, spleen and lymph nodes, and thus contributed to chimerism induction and extended face transplant survival.

The rationale to use our well established non-myeloablative induction therapy, of 7 day protocol of anti- $\alpha \beta$-TCR $\mathrm{mAb}$ and $\mathrm{CsA}$, was based on the selective elimination of about $95 \%$ of the $\mathrm{T}$ lymphocytes bearing $\alpha \beta$ chains, but sparing the $\gamma \delta \mathrm{T}$ cells (Klimczak et al. 2007; Siemionow et al. 2003b). $\gamma \delta \mathrm{T}$ cells regulate local immune response effectors in the skin, lung, intestine and central nervous system (Nanno et al. 2007), and support immunomodulatory effects (Fujihashi et al. 1999). Anti- $\alpha \beta-T C R$ mAb have been successfully used in cardiac (Heidecke et al. specific chimerism $\left(\mathrm{RT}^{\mathrm{a}+}\right)$ in the recipient peripheral blood (f) and bone marrow (g). Kinetics of $\mathrm{CD} 4^{+} / \mathrm{CD} 25^{+}$T-cell numbers (h), peaking on day 21 , at $2.83 \%$, during acute rejection process, for BMC, $1.32 \%$ for DRCC and $1.85 \%$ for MSC, with no significant difference between groups

1995), renal (Heidecke et al. 1998), and VCA (Siemionow et al. 2002) transplants. CsA, used as a part of our immunosuppressive protocol, does not affect hematopoiesis and preserves immunomodulatory effects of MSC (Le Blanc et al. 2004). However, CsA has been reported to interfere with regulatory $\mathrm{T}$ cells (Wang et al. 2006).

The post-depletional fraction of donor $\mathrm{T}$ lymphocytes and other cells of donor origin, including: B lymphocytes $\left(\mathrm{RT}^{\mathrm{a}+} / \mathrm{CD} 45 \mathrm{RA}^{+}\right)$, granulocytes, monocytes and dendritic cells $\left(\mathrm{RT}^{\mathrm{a}+} / \mathrm{CD} 11 \mathrm{~b} / \mathrm{c}^{+}\right)$, were responsible for the development of the donor-specific chimerism. The levels of donor chimerism (ranging 42-66\%) detected in the peripheral blood of the recipients on day 7 PT may be explained by the amount of the co-transplanted cells (specifically, $100 \times 10^{6} \mathrm{BMC}$ ). The number and the type of co-transplanted cells may account for the observed differences in chimerism levels between the groups. We injected $5 \times 10^{8}$ of nucleated cells per kilogram of donor $\mathrm{BMC}$ as supportive therapy, based on our previous findings (Klimczak et al. 2007) and clinical reports of donor BMC co-transplantation in solid organs $\left(2 \times 10^{8}-3 \times 10^{8} \mathrm{BMC} /\right.$ $\mathrm{kg})\left(\right.$ Herve 2003). The dose of $5 \times 10^{6} \mathrm{MSC}\left(2.5 \times 10^{7}\right.$ $\mathrm{MSC} / \mathrm{kg}$ ) was based on the reports on the rat heart transplantation model where a total dose of $2 \times 10^{6}$ MSC was delivered intravenously (Popp et al. 2008), In addition, we considered the dose based on the clinical experience with MSC where dosages of $1-9 \times 10^{6}$ to $1-2 \times 10^{7}$ were administered for treatment of graft-versus-host disease (Lin and Hogan 2011). In our study, all cell therapies were delivered via an intraosseous route, to prevent development of the adverse effects associated with intravenous 
injections, such as e.g., emboli formation (Inoue et al. 2006), as well as to limit cell sequestration in the liver or spleen (Itakura et al. 2007) and finally to allow for induction and maintenance of high levels of chimerism (Klimczak et al. 2007).

Table 2 shows a comparison between current study and our published data on chimerism induction following intraosseous BMC delivery without VCA-under 7-day anti- $\alpha \beta-T C R$ mAb-CsA immunosuppression protocol (Klimczak et al. 2007) which was tested in fully mismatched $\mathrm{ACI}\left(\mathrm{RT}^{\mathrm{a}}{ }^{\mathrm{a}}\right)$-to-Lewis(RT1 $\left.{ }^{1}\right)$ VCA transplants of inguinal flap (Demir et al. 2005) or hemiface allografts (Siemionow et al. 2005). The cells of donor origin migrating from the allograft, contributed to the development of chimerism (Siemionow et al. 2005) and $45 \%$ of chimerism detected in group 1 on day 7 PT originated from the transplant. Indeed, our previous study on MHC class I-mismatched face allografts without VBM component or supportive BMC therapies, revealed high levels of donor chimerism in both the CD4 (17\%) and CD8 (9\%) T-cell populations which correlated with long term survival of face transplant recipients (Siemionow et al. 2005). However, our previous study differed from the current report since the immunosuppressive protocol was based on tapered dose of CsA maintenance monotherapy. In the current model, both the donor BMC and the cells resident in the face transplant contributed to the peripheral blood chimerism. The abundant lymph nodes in the facial allotransplant could contribute to the higher donor cell chimerism compared to a groin flap VCA (Demir et al. 2005). However, the face survival was shorter compared to the groin VCA. We previously reported $8-11 \%$ of total peripheral blood chimerism after intraosseous or intravenous transplantation of $70 \times 10^{6} \mathrm{ACI} B M$ cells in Lewis rats treated with a 7-day anti- $\alpha \beta$-TCR mAb-CsA protocol (Klimczak et al. 2007). In current study, chimerism levels of 55-65 \% reported in group 2 (face and BMC co-transplantation) on day 7 post-transplant are consistent with these findings.

The time interval between transplantation and face allograft rejection was too short to observe the complete disappearance of the circulating CC. Chimerism levels fell rapidly after peaking at 1 week PT, and this decrease in chimerism correlated with transplant rejection with low chimerism levels still persisting at the time of full rejection. It remains unclear whether chimerism is required for tolerance maintenance or is a consequence of donor-specific unresponsiveness. Experimental models of skin and renal transplantation involving donor cell depletion with donorspecific antibodies (Masli et al. 2000; Wren et al. 1992) have suggested that chimerism is involved in tolerance induction. The risk that the donor-specific antibodies are targeting the transplant was of concern. Thus, we have chosen co-transplantation of $\mathrm{CC}$ after their isolation from the primary chimeras.

The total chimerism levels in the peripheral blood were similar after CC or unselected BMC delivery; however, the levels of $\mathrm{B}$-cell and $\mathrm{CD} 90^{+}$progenitor cells of donor origin were higher after BMC co-transplantation (group 2). The higher number of progenitor cells in the BMC preparation may account for higher levels of $\mathrm{RT}^{\mathrm{a}+} / \mathrm{CD} 90^{+}$progenitors detected in the BM compartment between days 7 and

Table 2 Current and previously published results on chimerism and VCA transplant survival under different protocols

\begin{tabular}{|c|c|c|c|c|c|c|c|c|c|}
\hline \multirow{2}{*}{\multicolumn{2}{|c|}{ Study }} & \multirow{2}{*}{$\begin{array}{l}\text { VCA } \\
\text { trans- } \\
\text { plant }^{\mathrm{A}}\end{array}$} & \multirow{2}{*}{$\begin{array}{l}\text { Immuno- } \\
\text { suppressive } \\
\text { therapy }\end{array}$} & \multirow{2}{*}{$\begin{array}{l}\text { Intra-osseous donor } \\
\text { BMC injection }\end{array}$} & \multirow{2}{*}{$\begin{array}{l}\text { Transplant survival } \\
\text { (days) mean or [range] }\end{array}$} & \multicolumn{4}{|c|}{ Chimerism in blood on day 21} \\
\hline & & & & & & $\begin{array}{l}\text { Total } \\
\mathrm{RT}^{\mathrm{a}} \\
(\%)\end{array}$ & $\begin{array}{l}\mathrm{RT} 1 \% \\
\mathrm{CD} 4 \\
(\%)\end{array}$ & $\begin{array}{l}\mathrm{RT} 1 \% \\
\text { CD8 } \\
(\%)\end{array}$ & $\begin{array}{l}\mathrm{RT} 1 \% \\
\mathrm{CD} 45 \mathrm{RA} \\
(\%)\end{array}$ \\
\hline \multicolumn{2}{|c|}{$\begin{array}{l}\text { Siemionow et al. } \\
\text { (2005) }\end{array}$} & Hemi-face & $\mathrm{CsA}^{\mathrm{C}}$ & No & {$[196-330]$} & 14.1 & 9.6 & 4.2 & 0.3 \\
\hline \multicolumn{2}{|c|}{$\begin{array}{l}\text { Demir et al. } \\
\text { (2005) }\end{array}$} & Groin flap & $\begin{array}{c}7 \text { days } \alpha \beta-\mathrm{TCR} \\
\mathrm{mAb} / \mathrm{CsA}^{\mathrm{D}}\end{array}$ & & 59 & 20.5 & 14 & 6.5 & 0 \\
\hline \multirow{2}{*}{\multicolumn{2}{|c|}{$\begin{array}{l}\text { Klimczak et al. } \\
\text { (2007) }\end{array}$}} & $\mathrm{NA}^{\mathrm{B}}$ & & $35 \times 10^{6}$ & $\mathrm{NA}^{\mathrm{B}}$ & 6.5 & 3.8 & 1.8 & 0.8 \\
\hline & & & & $70 \times 10^{6}$ & & 7.8 & 5.4 & 1.6 & 0.7 \\
\hline \multirow[t]{2}{*}{$\begin{array}{r}\text { Current } \\
\text { study }\end{array}$} & $\begin{array}{c}\text { Group } \\
1\end{array}$ & Hemi-face & & No & 27 & 9.7 & 9.1 & 3.7 & 0.4 \\
\hline & $\begin{array}{l}\text { Group } \\
2\end{array}$ & & & $100 \times 10^{6}$ & 35 & 15.6 & 12.3 & 6.1 & 2.4 \\
\hline
\end{tabular}

A All studies based on fully MCH class I mismatch VCA transplantations from ACI donors to Lewis recipients

${ }^{\text {B }}$ Comparison of donor BMC introsseous and intravenous injection

C Continuous CsA immunosuppressive protocol: CsA $16 \mathrm{mg} / \mathrm{kg} /$ day for 7 days, then tapered to $2 \mathrm{mg} / \mathrm{kg} / \mathrm{day}$ (over 4 weeks) and maintained at this level thereafter

D 7 days anti- $\alpha \beta$-TCR mAb/CsA immunosuppressive protocol: $250 \mathrm{mg} / \mathrm{day} \alpha \beta$-TCR plus $16 \mathrm{mg} / \mathrm{kg}$ CsA for 7 days 
35 PT in the MSC and CC groups, thus contributing to higher levels of chimerism in the peripheral blood. The chimerism level of the donor B-cell lineage increased significantly over the time after BMC delivery when compared to groups with MSC or CC co-transplantation, confirming the engraftment and proliferation of donor BMC progenitors. A transition from T-cell to B-cell chimerism predominance was observed on day $21 \mathrm{PT}$ for the BMC group. An increase in donor origin B-cell chimerism specifically seen in the B-cell progenitors/precursors population was also observed after CC delivery. Interestingly we have not observed increase in B-cell chimerism in group receiving supportive therapy with donor MSC. This should be explained by the absence of hematopoietic precursors and B-cell progenitors, within the MSC population. We have previously reported that following face transplantation without VBM component (Siemionow et al. 2003a, 2005) we observed chimerism with a T-cell lineage predominance. In contrast, in transplants including VBM component (Kulahci et al. 2010; Siemionow et al. 2003b) chimerism was characterized by B-cell lineage predominance. We have reported that B-cell progenitors (over $10 \%$ of cells) present in the VBM component of allograft (Siemionow et al. 2008), accounted for maintenance of the B-cell chimerism over longer period of time compared to the chimerism maintenance observed after intravenous BMC transplantation We have also reported differences in chimerism levels observed after intravenous vs. intraosseous bone marrow transplantation (Klimczak et al. 2007).

The short timeline for donor cells engraftment, differentiation and detection in the peripheral blood, as shown for the B cells in group 2 and 4, relies on the combination of a non-myeloablative protocol with intraosseous transplantation of the donor origin cells. For engraftment, proliferation and differentiation the progenitor cells require microenvironment provided by bone marrow niche allowing for direct interaction with MSC (Janczewska et al. 2003) and this microenvironment was warranted by direct intraosseous BMC delivery. Moreover, short-term immunodepletive protocol of anti- $\alpha \beta$-TCR mAb, used in this study, did not affect B-cell precursors and allowed for their rapid engraftment and reconstitution. Rapid lymphoid recovery, observed 10 days after VBM transplantation, was previously reported in lethally irradiated rats (Janczewska et al. 2003). Intraosseous transplantation of BMC, MSC as well as in vivo created CC, delivers these cells directly into natural bone marrow environment allowing for immediate recovery of the hematopoietic cell activity. We reported similar results after VBM (Siemionow et al. 2008) and after intraosseous (Klimczak et al. 2007) cells transplantation in non-irrradiated rats. This approach may have contributed for development of operational tolerance achieved in our different VBM transplantation study using fully MHC- mismatched hind-limb transplant model under the same immunosuppressive protocol (Siemionow et al. 2003b). Finally, CsA, which is known to inhibit $\mathrm{T}$ lymphocyte proliferation, with no direct effect on B cells (Boldt et al. 2006; Heidt et al. 2008), may have influenced the B/T cell ratios of recipient and donor cells. The absence of costimulatory molecules on immature B cells causes $\mathrm{CD} 4^{+}$ T-cell anergy, as reported in vitro (Parker 1993) and in vivo (Niimi et al. 1998; Yan et al. 2002). Donor-derived $\mathrm{B}$ cells also specifically delete donor-reactive $\mathrm{CD}^{+} \mathrm{T}$ cells (Fehr et al. 2008). The only study, reporting donor-specific tolerance to be independent of donor B cells, involved the use of B-cell deficient rats and continuous anti-B-cell mAb administration. However, the elimination of B cells was incomplete (Yokoi et al. 1999).

This is the first report on the application of different cellular therapies in a face transplantation model. MSC administration resulted in lower levels of chimerism induction compared to other cell therapy groups, however, despite lower chimerism levels, MSC therapy improved allograft survival. Lower level of chimerism in MSC therapy group is not surprising because MSC are not hematopoietic cells, thus will not contribute to chimerism directly, and their distribution to the periphery is limited. In this study we have relied on the immunomodulatory properties of MSC. MSC decrease T-cell activation in vivo, probably by inhibiting dendritic cell maturation and antigen-presenting function, as well as proliferation and maturation of T cells (Beyth et al. 2005; Inoue et al. 2006); B cells (Corcione et al. 2006) in vitro. These features support their use to treat transplant rejection and GvHD (Le Blanc and Ringden 2007) in solid organs and bone marrow transplantation respectively. However, doubts remain about the immunomodulatory properties of the MSCs in vivo, since injection of donor MSC has been reported to either prolong (Bartholomew et al. 2002) or shorten (Inoue et al. 2006; Sbano et al. 2008) allograft survival. Finally, MSCs inhibit the afferent phase of alloreactivity, but not the cytotoxic effects of the activated $\mathrm{T}$ cells (Rasmusson et al. 2003).

We used $\mathrm{CC}$ isolated from $\mathrm{ACI} /$ Lewis chimeras to investigate the effect of these cells alone, on the face allografts survival. We found that $17-50 \%$ of the cells of donor origin positively selected from primary chimeras on the basis of donor MHC class I (group 4) presented both the donor (ACI, $\mathrm{RT}^{\mathrm{a}}{ }^{\mathrm{a}}$ ) and recipient (Lewis, $\mathrm{RT} 1^{1}$ ) $\mathrm{MHC}$ class I antigens. We named these cells "donor/recipient chimeric cells". DRCC resulted from fusion of the donor and recipient progenitors present within the BM compartment of the primary chimeras (Terada et al. 2002). Presence of DRCC has been described experimentally, in liver transplantation and BM transplantation (Wang et al. 2003), and in studies on intestine (Rizvi et al. 2006), heart 
(Nygren et al. 2004), kidney (Bonde et al. 2010) and VCA (Ajiki et al. 2005) transplantation. The survival and impact of DRCC is unknown (Kashofer et al. 2006) and these cells may simply result either from in vivo cell fusion or from the transfer of plasma membrane fragments (trogocytosis) (Yamanaka et al. 2009). Trogocytosis is the mechanism when large amounts of surface proteins can be transferred between the cells. In the absence of a nuclear cell fusion a fragments of membrane may be exchanged between the donor and recipient cell. The potential mechanism of action of DRCC may be either direct through cell-to-cell interactions or indirect by secretion of anti-inflammatory factors. The CCs share MHC class I originating from both the donor $\left(\mathrm{ACI}, \mathrm{RT}^{\mathrm{a}}{ }^{\mathrm{a}}\right.$ ) and the recipient (Lewis, $\mathrm{RT} 1^{1}$ ). DRCC migrated and engraft to the lymphoid organs during the window of immunological silence supported by a short term of anti- $\alpha \beta-\mathrm{TCR} \mathrm{mAb} / \mathrm{Cs} \mathrm{A}$ protocol. By presenting antigens including MHC class I of both the donor and recipient, DRCC may educate recipient regulatory cells (regulatory $\mathrm{T}$ cells $\mathrm{B}$ cells and macrophages) allowing for graft acceptance. As reported by Chow and co-workers (2013), the transfer of host MHC class I molecules to transplanted donor cells permit their self identity and protect from detection by the host NK cells and macrophages.

We assume that DRCC, expressing both the donor and recipient MHC class I antigens, may facilitate allograft acceptance by modulating the immune responses. To the best of our knowledge this is the first report on application of DRCC as a supportive therapy in VCA, resulting in the extension of facial allograft survival. We will investigate this hypothesis further, to clarify the role of DRCC in the face transplantation outcomes.

Furthermore, a population of $\mathrm{T}$ cells expressing $\mathrm{CD}^{+} /$ $\mathrm{CD} 25^{+}$was detected in our rat face transplantation model.

The low levels of $\mathrm{CD} 4^{+} / \mathrm{CD} 25^{+} \mathrm{T}$ cells 1 week after transplantation in this study may be due to the anti- $\alpha \beta-\mathrm{TCR}$ $\mathrm{mAb}$ inactivating all $\mathrm{T}$ lymphocytes bearing $\alpha \beta$-TCR and by CsA inhibiting the production of IL-2, a cytokine required for $\mathrm{CD}^{+} / \mathrm{CD} 25^{+}$T-cell development (Noris et al. 2007). Then, the level of $\mathrm{CD} 4^{+} / \mathrm{CD} 25^{+} \mathrm{T}$-cell population increased during the T-cell recovery period. The increase of the $\mathrm{CD} 4^{+} / \mathrm{CD} 25^{+}$cell subset levels was also observed during rejection time. The $\mathrm{CD} 4{ }^{+} \mathrm{CD} 25^{+} \mathrm{T}$ cells subset studied in blood has to be considered as both reactive and immunomodulatory cells, including activated alloreactive and regulatory $\mathrm{CD}^{+}{ }^{+} \mathrm{T}$ lymphocytes. This might explain its increase occurred at the onset of rejection, as reported in liver and kidney allograft recipients (Bunnag et al. 2008; Veronese et al. 2007). A study of the T-regulatory subset through a $\mathrm{CD} 4{ }^{+} \mathrm{CD} 25^{\text {high }}$ gating was limited by the absence of consensual threshold (MFI or percentage) to consider cells as $\mathrm{CD} 25^{\text {high }}$ among the $\mathrm{CD} 25^{+}$ones (Bryl et al. 2009; Pinheiro et al. 2011; Strauss et al. 2007). This would justify a FOXP3 assessment of the infiltrating cell subsets in the transplant in further studies on the current model. The development of regulatory or alloreactive immune reactions in skin and draining lymph nodes, limits the interpretation of this $\mathrm{CD} 4{ }^{+} \mathrm{CD} 25^{+}$cell subset in blood, that might be naturally occurring $\mathrm{T}$ regulatory cells or alloreactive cells.

This study is an exploratory investigation comparing the effect of different cellular therapies on the face allograft survival in a setting of VCA transplantation. Based on the promising results, this study serves as a foundation for future investigations, where extension of face allograft survival can be tested following different timing of cell delivery and different cell dosages. In summary, this study confirmed that all cellular therapies extended significantly face allograft survival compared to the controls. Allografts supported with unprocessed BMC showed the longest survival. Both, the MSC and in vivo created CC therapy contributed to prolonged facial allograft survival due to their immunomodulatory properties. However, despite maintenance of donor specific chimerism tolerance was not achieved. Cellular therapies with donor origin cells have potential for clinical applications as suggested by recent reports in kidney (Kawai et al. 2014) and VCA transplantations (Gorantla et al. 2011; Hequet et al. 2008). However, before introduction of these therapies to the clinical practice, further studies are needed to assess the efficacy, kinetics and immunomodulatory properties of the transplanted MSC and DRCC.

Acknowledgments This entire project, including cost of experiments, imaging cores and facilities and authors' salaries, was funded by the grants of the senior author (Maria Siemionow $\mathrm{MD}, \mathrm{PhD}$ ) and was performed at the Microsurgery Research Laboratory of the Department of Plastic Surgery at Cleveland Clinic. The first author received personal travel support (funding not transferred to the Cleveland Clinic) from the French Academy of Medicine and Foundation Philippe. We would like to thank Ms Tracy Folger for editing the manuscript.

\section{Compliance with ethical standards}

Ethical approval All applicable international, national and institutional guidelines for the care and use of animals were followed. All procedures performed in studies involving animals were in accordance with the ethical standards of the institution at which the studies were conducted.

\section{References}

Ajiki T et al (2005) Composite tissue transplantation in rats: fusion of donor muscle to the recipient site. Transplant Proc 37:208-209

Bartholomew A et al (2002) Mesenchymal stem cells suppress lymphocyte proliferation in vitro and prolong skin graft survival in vivo. Exp Hematol 30:42-48 
Beyth S et al (2005) Human mesenchymal stem cells alter antigenpresenting cell maturation and induce T-cell unresponsiveness. Blood 105:2214-2219

Boldt A et al (2006) The influence of immunosuppressive drugs on Tand B-cell apoptosis via p53-mediated pathway in vitro and in vivo. Transplantation $82: 422-427$

Bonde $\mathrm{S}$ et al (2010) Cell fusion of bone marrow cells and somatic cell reprogramming by embryonic stem cells. FASEB J 24:364-373

Bryl E et al (2009) Human CD4low CD25high regulatory $\mathrm{T}$ cells indiscriminately kill autologous activated $\mathrm{T}$ cells. Immunology 128(1 suppl):e287-e295

Buhler LH et al (2002) Induction of kidney allograft tolerance after transient lymphohematopoietic chimerism in patients with multiple myeloma and end-stage renal disease. Transplantation 74:1405-1409

Bunnag S et al (2008) FOXP3 expression in human kidney transplant biopsies is associated with rejection and time post transplant but not with favorable outcomes. Am J Transplant 8:1423-1433

Buttemeyer R et al (1996) Rejection of the component tissues of limb allografts in rats immunosuppressed with FK-506 and cyclosporine. Plast Reconstr Surg 97:139-148 (discussion 149-151)

Chow T et al (2013) The transfer of host MHC class I protein protects donor cells from NK cell and macrophage, Äêmediated rejection during hematopoietic stem cell transplantation and engraftment in mice. Stem Cells 31:2242-2252

Corcione A et al (2006) Human mesenchymal stem cells modulate B-cell functions. Blood 107:367-372

Demir Y et al (2005) Strategies to develop chimerism in vascularized skin allografts across MHC barrier. Microsurgery 25:415-422

Dominici $M$ et al (2006) Minimal criteria for defining multipotent mesenchymal stromal cells. The International Society for Cellular Therapy position statement. Cytotherapy 8:315-317

Dubernard JM et al (2007) Outcomes 18 months after the first human partial face transplantation. N Engl J Med 357:2451-2460

Fehr T et al (2008) Rapid deletional peripheral CD8 T cell tolerance induced by allogeneic bone marrow: role of donor class II MHC and B cells. J Immunol 181:4371-4380

Foster RD et al (1998) Donor-specific tolerance induction in composite tissue allografts. Am J Surg 176:418-421

Fujihashi K et al (1999) Gammadelta T cells regulate mucosally induced tolerance in a dose-dependent fashion. Int Immunol 11:1907-1916

Gibson T, Medawar PB (1943) The fate of skin homografts in man. J Anat 77(4):299-310

Gorantla VS et al (2011) Favoring the risk-benefit balance for upper extremity transplantation-the Pittsburgh Protocol. Hand Clin 27:511-520

Hackshaw A (2009) Setting up, conducting and reporting trials. In: Hackshaw A (ed) A concise guide to clinical trials. BMJ Books, Chichester, WS, pp 157-186

Heidecke CD et al (1995) alpha/beta-T cell receptor-directed therapy in rat cardiac allograft recipients. Treatment prior to alloantigen exposure prevents sensitization and abrogates accelerated rejection. Transplantation 59:78-84

Heidecke CD et al (1998) Importance of $\mathrm{T}$ cells to accelerated rejection and acceptance of renal allografts in sensitized rat recipients. Transplantation 66:1354-1361

Heidt $\mathrm{S}$ et al (2008) Effects of immunosuppressive drugs on purified human B cells: evidence supporting the use of MMF and rapamycin. Transplantation 86:1292-1300

Hequet $\mathrm{O}$ et al (2008) Allogeneic donor bone marrow cells recovery and infusion after allogeneic face transplantation from the same donor. Bone Marrow Transplant 41:1059-1061

Herve P (2003) Donor-derived hematopoietic stem cells in organ transplantation: technical aspects and hurdles yet to be cleared. Transplantation 75(9 suppl):55S-57S
Inoue $S$ et al (2006) Immunomodulatory effects of mesenchymal stem cells in a rat organ transplant model. Transplantation 81:1589-1595

Itakura $S$ et al (2007) Mesenchymal stem cells facilitate the induction of mixed hematopoietic chimerism and islet allograft tolerance without GVHD in the rat. Am J Transplant 7:336-346

Janczewska S et al (2003) Fast hematopoietic recovery after bone marrow engraftment needs physiological proximity of stromal and stem cells. Cell Transplant 12:399-406

Jones NF et al (2001) Comparison of long-term immunosuppression for limb transplantation using cyclosporine, tacrolimus, and mycophenolate mofetil: implications for clinical composite tissue transplantation. Plast Reconstr Surg 107:777-784

Kashofer K et al (2006) In vivo formation of unstable heterokaryons after liver damage and hematopoietic stem cell/progenitor transplantation. Stem Cells 24:1104-1112

Kawai $\mathrm{T}$ et al (1995) Mixed allogeneic chimerism and renal allograft tolerance in cynomolgus monkeys. Transplantation 59:256-262

Kawai $\mathrm{T}$ et al (2008) HLA-mismatched renal transplantation without maintenance immunosuppression. N Engl J Med 358:353-361

Kawai $\mathrm{T}$ et al (2014) Long-term results in recipients of combined HLA-mismatched kidney and bone marrow transplantation without maintenance immunosuppression. Am J Transplant 14:1599-1611

Klimczak A et al (2007) Donor-origin cell engraftment after intraosseous or intravenous bone marrow transplantation in a rat model. Bone Marrow Transplant 40:373-380

Kulahci Y et al (2010) Long-term survival of composite hemiface/mandible/tongue allografts correlates with multilineage chimerism development in the lymphoid and myeloid compartments of recipients. Transplantation 90:843-852

Kuo YR et al (2009) Mesenchymal stem cells prolong composite tissue allotransplant survival in a swine model. Transplantation 87:1769-1777

Lantieri L et al (2011) Feasibility, reproducibility, risks and benefits of face transplantation: a prospective study of outcomes. Am J Transplant 11:367-378

Le Blanc K, Ringden O (2007) Immunomodulation by mesenchymal stem cells and clinical experience. J Intern Med 262:509-525

Le Blanc $K$ et al (2004) Mesenchymal stem cells inhibit the expression of CD25 (interleukin-2 receptor) and CD38 on phytohaemagglutinin-activated lymphocytes. Scand J Immunol 60:307-315

Lee WP et al (1991) Relative antigenicity of components of a vascularized limb allograft. Plast Reconstr Surg 87:401-411

Lin Y, Hogan WJ (2011) Clinical application of mesenchymal stem cells in the treatment and prevention of graft-vs.-host disease. Adv Hematol 2011:427863

Masli S et al (2000) Requirement for early donor cell chimerism during prolonged survival of murine skin allografts. Transplantation 69:1667-1675

Mathew JM et al (2000) Involvement of multiple subpopulations of human bone marrow cells in the regulation of allogeneic cellular immune responses. Transplantation 70:1752-1760

Monaco AP et al (1976) Possible active enhancement of a human cadaver renal allograft with antilymphocyte serum (ALS) and donor bone marrow: case report of an initial attempt. Surgery 79:384-392

Murray JE (1971) Organ transplantation (skin, kidney, heart) and the plastic surgeon. Plast Reconstr Surg 47:425-431

Nanno M et al (2007) Gammadelta T cells: firefighters or fire boosters in the front lines of inflammatory responses. Immunol Rev 215:103-113

Niimi M et al (1998) Donor resting B cells induce indefinite prolongation of fully allogeneic cardiac grafts when delivered with anti-immunoglobulin-D monoclonal antibody: evidence for 
tolerogenicity of donor resting B cells in vivo. Transplantation 66:1786-1792

Noris M et al (2007) Regulatory T cells and T cell depletion: role of immunosuppressive drugs. J Am Soc Nephrol 18:1007-1018

Nygren JM et al (2004) Bone marrow-derived hematopoietic cells generate cardiomyocytes at a low frequency through cell fusion, but not trans differentiation. Nat Med 10:494-501

Parker DC (1993) T cell-dependent B cell activation. Annu Rev Immunol 11:331-360

Pinheiro D et al (2011) Phenotypic and functional characterization of a CD4+ CD25high FOXP3high regulatory T-cell population in the dog. Immunology 132:111-122

Popp FC et al (2008) Mesenchymal stem cells can induce long-term acceptance of solid organ allografts in synergy with low-dose mycophenolate. Transpl Immunol 20:55-60

Rasmusson I et al (2003) Mesenchymal stem cells inhibit the formation of cytotoxic $\mathrm{T}$ lymphocytes, but not activated cytotoxic $\mathrm{T}$ lymphocytes or natural killer cells. Transplantation 76:1208-1213

Rizvi AZ et al (2006) Bone marrow-derived cells fuse with normal and transformed intestinal stem cells. Proc Natl Acad Sci USA 103:6321-6325

Sbano P et al (2008) Use of donor bone marrow mesenchymal stem cells for treatment of skin allograft rejection in a preclinical rat model. Arch Dermatol Res 300:115-124

Schneeberger S et al (2013) Upper-extremity transplantation using a cell-based protocol to minimize immunosuppression. Ann Surg 257:345-351

Siemionow $\mathrm{M}$ et al (2002) Induction of tolerance in composite-tissue allografts. Transplantation 74:1211-1217

Siemionow $M$ et al (2003a) Functional tolerance following face transplantation in the rat. Transplantation 75:1607-1609

Siemionow MZ et al (2003b) Donor-specific tolerance in fully major histocompatibility major histocompatibility complex-mismatched limb allograft transplants under an anti-alphabeta $\mathrm{T}$-cell receptor monoclonal antibody and cyclosporine A protocol. Transplantation 76:1662-1668

Siemionow M et al (2005) Development and maintenance of donorspecific chimerism in semi-allogenic and fully major histocompatibility complex mismatched facial allograft transplants. Transplantation 79:558-567
Siemionow M et al (2008) Hematopoietic stem cell engraftment and seeding permits multi-lymphoid chimerism in vascularized bone marrow transplants. Am J Transplant 8:1163-1176

Siemionow $\mathrm{M}$ et al (2009) Near-total human face transplantation for a severely disfigured patient in the USA. Lancet 374:203-209

Starzl TE et al (1992) Cell migration, chimerism, and graft acceptance. Lancet 339:1579-1582

Strauss L et al (2007) Selective survival of naturally occurring human $\mathrm{CD} 4+\mathrm{CD} 25+$ Foxp 3 + regulatory $\mathrm{T}$ cells cultured with rapamycin. J Immunol 178:320-329

Terada $\mathrm{N}$ et al (2002) Bone marrow cells adopt the phenotype of other cells by spontaneous cell fusion. Nature 416:542-545

Veronese $\mathrm{F}$ et al (2007) Pathological and clinical correlates of FOXP3 + cells in renal allografts during acute rejection. Am J Transplant 7:914-922

Wang X et al (2003) Cell fusion is the principal source of bonemarrow-derived hepatocytes. Nature 422:897-901

Wang $\mathrm{H}$ et al (2006) A potential side effect of cyclosporin A: inhibition of $\mathrm{CD} 4(+) \mathrm{CD} 25(+)$ regulatory $\mathrm{T}$ cells in mice. Transplantation 82:1484-1492

Woollett GR et al (1985) Molecular and antigenic heterogeneity of the rat leukocyte-common antigen from thymocytes and $\mathrm{T}$ and $\mathrm{B}$ lymphocytes. Eur J Immunol 15:168-173

Wren SM et al (1992) The requirement for allogeneic chimerism for second transfer of tolerance from mixed allogeneic chimeras $(\mathrm{A}+\mathrm{B}->\mathrm{A})$ to secondary recipients. Transplantation 54:1031-1040

$\mathrm{Xu} \mathrm{H}$ et al (2013) Simultaneous bone marrow and composite tissue transplantation in rats treated with nonmyeloablative conditioning promotes tolerance. Transplantation 95:301-308

Yamanaka $\mathrm{N}$ et al (2009) Bone marrow transplantation results in human donor blood cells acquiring and displaying mouse recipient class $\mathrm{I}$ MHC and $\mathrm{CD} 45$ antigens on their surface. PLoS One 4:e8489

Yan Y et al (2002) Postoperative administration of donor B cells induces rat kidney allograft acceptance: lack of association with Th2 cytokine expression in long-term accepted grafts. Transplantation 73:1123-1130

Yokoi Y et al (1999) Origin, kinetics, and function of chimeric B lymphocytes in liver allografts. Transplantation 68:118-123 